\title{
An Investigation of Current Learning Processes: The Development of Residential Plumbing DIY Materials in a Township of Southern Taiwan
}

\author{
Feng-Chiao Chung, Chih-Cheng Lin \\ National Pingtung University of Science and Technology, Pingtung, Taiwan
}

\begin{abstract}
This study aims to investigate plumbing do it yourself (DIY) materials for development and practical issues in a township of Southern Taiwan and to explore the teaching process involved for adult student plumbing courses. Furthermore, innovative teaching strategies have been assessed as well. The research was based on the learning progress of 22 adult students taking plumbing DIY courses, held by Pingtung Township Public Library. After eight weeks of course work, satisfaction questionnaires and open-ended questions were used to explore their satisfaction. The study findings account for various arrangements of the workshop, the teaching processes, and related strategies. The plumbing courses include repair and replacement of lights, switch sockets, simple unclogging, etc. Through illustration, demonstration, hands-on operation, and interactive media, adult students' learning and interests were improved. The course and materials were highly praised by adult students; they all planned to take advanced courses in the near future.
\end{abstract}

Keywords: adult students, development of teaching materials, plumbing DIY, teaching strategies

\section{Introduction}

Currently, with the advancing development of information technology (IT) and increased knowledge of mass media, traditional teaching methods can no longer meet the needs of modern information. In addition, the prevalence of computer technology and its development of Internet communication indicate that its application is important in modern teaching.

Due to the impact of the low birth rate and people's negative impression about plumbers and electricians, fewer people devote themselves to those jobs. As a plumber and an electrician, it makes a difference to know and care about its role in society. In this sense, the researcher decided to conduct this research to make a contribution to those wanting to learn a trade. Applying computer auxiliary videos and smartphones to teaching not only makes them more attractive, but it is also compatible with traditional teaching methods (Gould, 2010). To achieve this goal, the researcher applied 20 years of practical maintenance experience into a tailor-made residential plumbing course with do it yourself (DIY) materials in Southern Taiwan. The materials were applied to the course to investigate their effects on adult students. As such, this paper aims to answer the following research questions:

Feng-Chiao Chung, Ph.D., professor, Graduate Institute of Technological and Vocational Education, National Pingtung University of Science and Technology.

Chih-Cheng Lin, master, graduate student, Graduate Institute of Technological and Vocational Education, National Pingtung University of Science and Technology. 
1. Development of residential plumbing DIY materials in a township of Southern Taiwan;

2. Investigation on teaching processes of adult students' residential plumbing DIY courses;

3. Exploration on the teaching strategies of residential plumbing DIY courses.

\section{Literature Review}

\section{Skill Learning Theory}

Skill-learning consists of multiple continuous movements, although appropriate systematic actions are also needed (Driscoll, 2005). Anyone lacking technical abilities can improve them by a series of educational and practical training (Katz, 2009). Learning skills are seen in three stages: cognition, stage of orientation, and automation (Kellogg, 2008).

Stage of cognition. At this stage, students imitate skills through observation. They learn from instructors' operations and demonstrations. As beginners, they are not yet cognizant about isolated motions. Hence, they need time to absorb the skills taught.

Stage of orientation. At this stage, students learn to link all movements into a more complicated action. That is, they have to connect all the small units and create a larger unit to carry out the skill. The ability to connect and orientate takes time and repetitive drills. It is the stage in which students can familiarize themselves with necessary skills.

Stage of automation. Over time, their skills become stable and mature, becoming fast and accurate with the acquired skills. Repetitive drills and operations are necessary in the learning process, for a greater level of proficiency. As the proverb goes, "Practice makes perfect”. To feel at ease with plumbing DIY skills, reflection, and reviews are critical as well. Learning skills are comprised of continuous movement and systematic cooperation (Jongbloed-Pereboom, Janssen, Steenbergen, \& Nijhuis-van der Sanden, 2012).

\section{Multimedia Video Teaching Relevant Theory}

The purpose of multimedia in class is to create good communication between students and instructors. Media like Facebook and LINE can clearly convey messages to students and make learning easier for them. Researchers in education believe that authentic learning environments have positive effects on students (Yunus, \& Salehi, 2012). It has been suggested that instructors apply digital videos for teaching (Lei, 2009). These include video descriptions, illustrations, and analysis for each unit, as well as role playing, group skill practices, and learning through concept mapping. By exchanging ideas with each other, along with instructor interaction, the teaching content is maximized.

With the aid of multimedia, this research provided multimedia and visual information, which is beneficial to learning and knowledge acquisition. Through arranging the classroom and the use of appropriate materials, student learning can be enhanced. Multimedia gives students a chance to learn more about concepts and content (Shih, Chuang \&, Hwang, 2010). With multimedia, instructors' skills will also be elevated, while the teaching content will be more interesting for students, creating a positive learning environment.

\section{The Application of Realia}

Based on the technology involved and the degree to which they match reality, simulation experiences can be low- to high-fidelity (Cant \& Cooper, 2010). The instructor uses many authentic materials to help students acquire a better understanding of the course. The literature reveals that simulation positive impacts student learning, given the integration of classroom theory and application (Lasater, Johnson, Ravert, \& Rink, 2014). 
The residential plumbing DIY workshop followed three stages for learning. Additionally, teaching principles on multimedia were employed. Hands-on operation and realia were used in the present study to promote adult student learning efficacy in regards to plumbing DIY.

\section{Methodology}

\section{The Instructor}

As a technical service advisor of the township, the researcher is a licensed and experienced technician with over 20 years of experience in plumbing. In this way, the teacher was eager to share his professional knowledge and experience with the general public.

As a native Taiwanese, the researcher always conversed with people in Taiwanese. In order to teach fluently, it was used to discuss ideas most of the time. Mandarin was used to assist the teaching process when adult students did not understand Taiwanese. The township is located in the Southern part of Taiwan. Its population is 22,172 and the area is $42.0187 \mathrm{~km}^{2}$. Agriculture is a main source of income and employment for villagers.

\section{Participants}

There were 22 adult students in the township, who were ranging from 26 to 69 years old: This included seven males and 15 females. Their educational backgrounds included senior high school to graduate school, while professions also included retired teachers, farmers, businessmen, translators, human resource agency workers, beauticians, and others. Limited by personnel, time, and facilities, we could not use random sampling here.

\section{Teaching Material}

In order to meet the needs of the general public, the researcher designed a questionnaire by applying his practical experience: It aimed to investigate topics for adult student needs. After compiling this, he adjusted the teaching content and the questionnaire with his advisor. The revised three-Likert scale questionnaires were put on the service counter of the township office and library for people to fill in. The chief of the village was invited to broadcast the news and elaborate on the content of the investigation for the general public. Multimedia, such as Facebook and LINE were included to share teaching information.

The topics of the DIY teaching materials were decided according to results from the 75 questionnaires that had been distributed, which involved:

(1) Repair and replacements of lights and fluorescent lamps (82.7\%);

(2) Replacements of switch sockets (80.0\%);

(3) Replacements of showerheads (80.0\%);

(4) Replacements of faucets (77.3\%);

(5) Simple unclogging of water pipes (73.3\%);

(6) Replacements of water tank components in toilets (68.0\%);

(7) Replacement of fuse breakers (66.7\%);

(8) Identifications of ammeters (65.3\%).

The teaching activities took place on Saturday from 2:30 p.m. to 4:30 p.m. in the township library. The courses lasted for eight weeks from January 23rd to March 19th, 2016. 


\section{Findings}

\section{Teaching Preparation and Curriculum Organization}

Bruner has pointed out that effective teaching helps students operate, imagine, and learn through guidance and direction. Effective teaching should be arranged around learning motivations, which have obvious incentives.

Typical teaching process. To be sure that all students can protect their safety in plumbing DIY courses, the topic during Week one is basic knowledge of electric safety rules, electricity, and water.

Electric safety rules. The sign below should be obvious to everyone, as we can see warning and caution signs on many home appliances. Its purpose is to warn people not to open the lid. The triangular sign on the left is to warn users that there are dangerous voltage levels inside the products. The triangular sign on the right indicates that they should read the guide book beforehand.

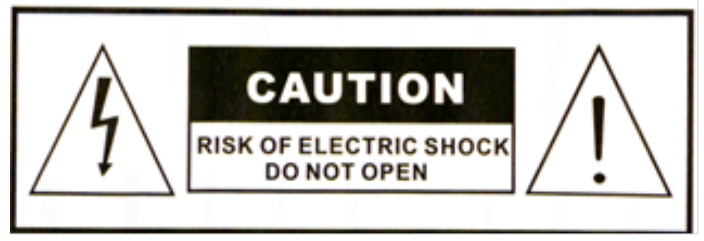

Figure 1. Sign of caution.

Plumbing and electricity maintenance are dangerous, so there are rules to bear in mind:

1. Never maintain home appliances barefoot: wear shoes outdoors and wear slippers indoors. Rubber-soled shoes are best. Make sure that your shoes are dry and insulated.

2. Never grab two wires at the same time when the power supply is on. Never grab wires with one hand, and touch the machine case or walls with the other hand, in order to prevent electric shock. Unplug the power cord before dismantling any appliances.

3. Never set up an antenna on rainy days, making sure no high voltage is nearby. Some appliances have high voltage (televisions and microwaves), so do not open the rear lids.

4. Always follow original specifications while changing machine parts. For example, never change a three-ampere fuse with a four-ampere fuse. It is not safe.

5. Always keep children away from the maintenance scene.

\section{Basic Knowledge of Electricity and Water}

This part includes Ohm's Law, electric power, direct current (DC), alternating current (AC), electric shock, source of domestic water, and charge of domestic water.

\section{Replacement and Maintenance of Faucets}

The steps to install four-hole kitchen sink faucets are:

(1) Turn off the faucet before installation;

(2) Dismantle the old faucet step by step;

(3) Release some water from the pipe to avoid impurity;

(4) Install the new faucet.

Watch the video on installation of faucets and showerheads (Test Rite Retail, 2011; 2015). 


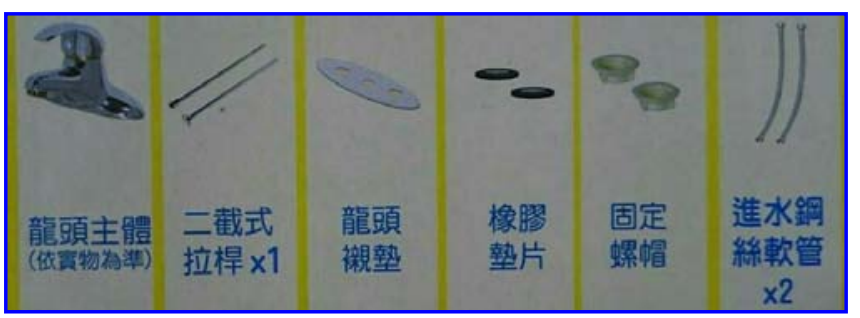

Figure 2. Parts of four-hole kitchen sink faucet.

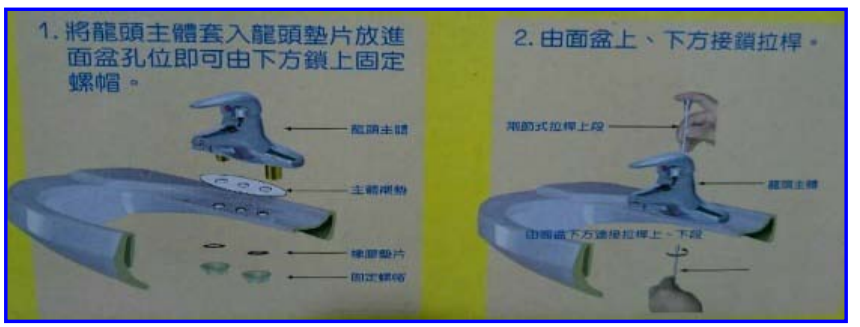

Figure 3. Instructional steps on installation.

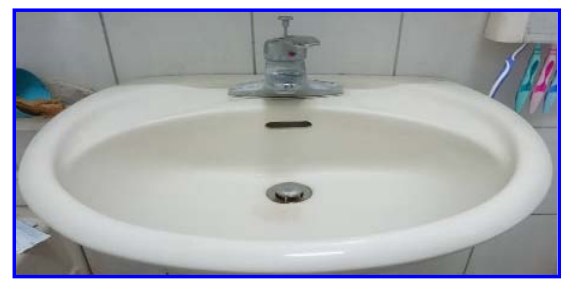

Figure 4. Completion of four-hole kitchen sink faucet.

\section{Replacement of showerheads}

The steps to install showerheads are:

1. Release the residual water, remains, sand, and impurities inside the pipe first;

2. Never use abrasive cleanser, rough or wire cloth, or corrosive cleanser to scrub faucet;

3. Dirt might remain on the bubbler and slow the water flow. Take out the inner filter from the bubbler, then clean and rinse it with small brush. Reinstall it.

4. Instructions:

(a) Put a cover on N-shape angle fittings, and tape five to six laps of the seal on screw thread;

(b) Turn off the faucet. Screw the N-shape angle fittings on both the hot and cold water holes separately;

(c) Check if the outfalls and faucet conform. Adjust it if it is uneven, then put a rubber gasket inside the rear nut of the faucet, and lock it on the N-shape angle fitting;

(d) Screw the nut tightly on the $\mathrm{N}$-shape angle fitting and lock it with a wrench;

(e) Lock the nuts with both hands first, although the junction will leak. Put in another plate, then seal the screw, but do not screw it too tightly;

(f) Put on the showerheads.

\section{Teaching Process}

Before the teaching. Preparation of class material. In order to make the teaching process effective and worthwhile, PowerPoint, pictures, and YouTube were adopted to introduce the content. To get students involved, authentic material and interactive questioning and answering have been helpful. 
Preparation of "plumbing DIY experiential learning" simulation. Accidents happen all the time in order to prevent them in advance, simulations of situations (both dynamic and static ones) are important. The arrangement of the classroom can promote learning motivation and get them involved. With appropriate topics and context setting, it is easy for students to learn more optimally. For instance, by utilizing the material components and realia in class, adult students can get involved without knowing it, as shown in Figure 5.

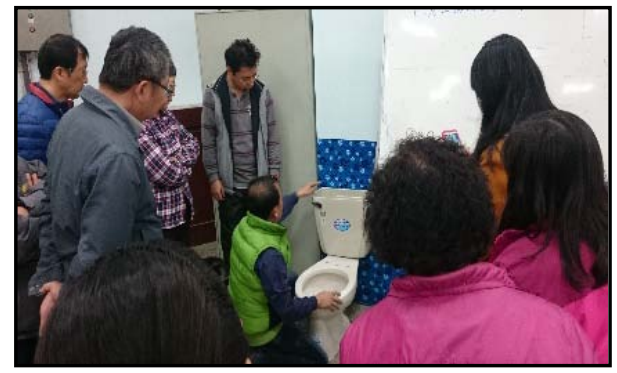

Figure 5. Utilization of the plumbing material in the teaching context.

The teaching process. Illustrations. Explain all steps to adult students through systematic decomposition: Break down the complicated plumbing work into simple actions. Demonstrate them step by step and involve adult students in the practical operation.

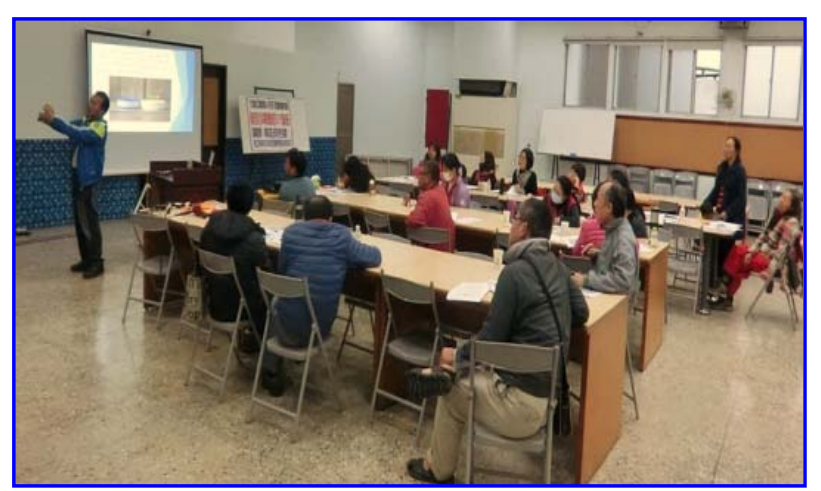

Figure 6. Explanation of teaching content before DIY courses.

Interactive questioning and answering. Adult students are encouraged to ask questions and share reflections. Through interactive teaching, they will have a better understanding of the principles. For example,

Student: Excuse me, teacher. What is the working voltage at home?

Instructor: The electricity we use at home is unidirectional dual current. The sockets for lamps, refrigerators, and TVs are 110 volts. However, air conditioners, electric boilers, and solar water heaters are 220 volts.

As the proverb goes “No pain, no gain”. Sufficient preparation before class is a key for every instructor's success. One must correct student steps to avoid accidents.

Hands-on operation. The practice of a hands-on method is crucial, largely since plumbing DIY has risks. The general public usually relies on professionals for the maintenance of plumbing. However, the inconvenience resulting from its malfunctioning made it necessary for adult students to acquire these plumbing DIY skills as well. However, simple plumbing DIY courses are not available in schools. Adult student interest and enthusiasm in the courses were evident, and through hands-on practices, they would be able to fix the plumbing problem at home, which will also give them a great sense of achievement. 
Below are questions students asked during a hands-on operation:

Student Lin: Excuse me, sir. Are the sizes of faucet apertures and threads the same? And why are they always put together with white tape?

Instructor: No, the sizes are different. There are $4 \mathrm{~mm}$ and $6 \mathrm{~mm}$ sizes. So, we need to pay attention when buying the materials. And the white tape is called thread seal tape. Its function is to prevent leakage of the faucet.

Student Lin: I understand. Thank you for your detailed explanation.

After teaching. Bruner stated that what matters in a student's learning process is the motivation to discover related issues and methods (Huang, 2002). The ultimate goal of the research was to help students understand and absorb the skills, i.e., to then apply what they acquired in their daily lives. Figure 7 shows immediate feedback and discussion in its explanation.

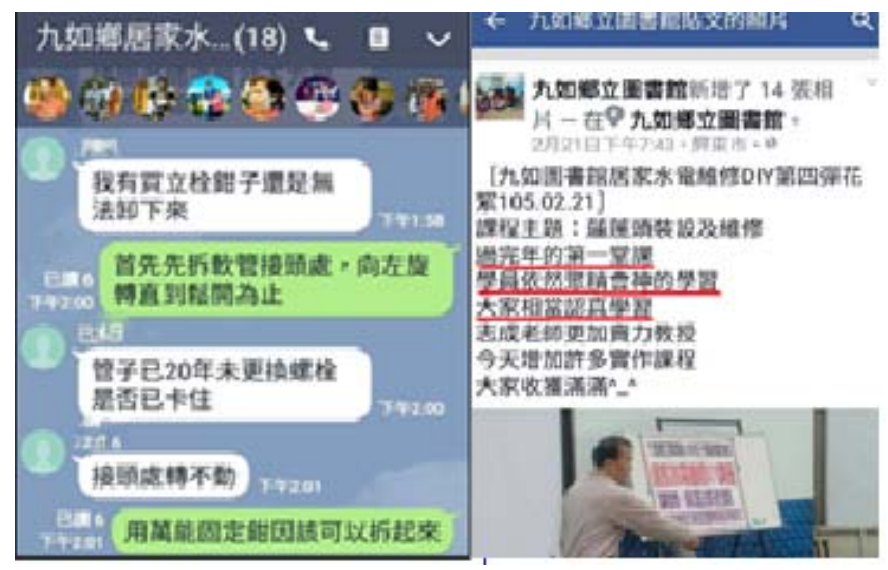

Figure 7. Mediation of modern technology for adult students to practice at home.

An after-course questionnaire was used to assess any doubts and questions students had about the courses, and to give instructors direction for future improvements, hopefully to elevate student interest in residential plumbing DIY.

After the workshop, students gave feedback and encouragement. Here are some quotes:

Student Chen: I gained a lot of confidence after the workshop. Now, I can install a showerhead by myself. The sense of achievement I had was beyond words.

Student Lin: I applied all the teaching courses into my daily life. I took pictures and notes of all the teaching content, and edited through my own words to help me memorize and learn.

Student Chen: I looked forward to each class, since the teacher introduced new components every week. I had a lot of fun buying material and doing DIY at home.

Student Tsai: I think the workshop was very useful and practical. Skills like installing a showerhead, drain pipes, and water tanks are practical to me, since I live alone. Discussing and learning with the teacher and fellow students was very helpful.

Satisfaction survey. During the eight-week course, questionnaires were used for each one. The percent of student satisfaction was above $80 \%$, indicating they were very satisfied and looking forward to future classes. A sample frequency distribution table for week five is shown in Table 1.

There were 19 students in the fifth week. According to Table 1, in Question 1, "I think the course gave me practical help”, 15 adult students were very satisfied (78.9\%) while four were satisfied (21.1\%). In Question 2, “The course was very practical”, 17 students were very satisfied (89.5\%) while two were satisfied (10.5\%). In 
Question 3, "The teaching environment was very comfortable”, 14 adult students were very satisfied (73.7\%) while five were satisfied (26.3\%). In Question 4, "I learned a lot after the course”, 14 adult students were very satisfied (73.7\%) while five were satisfied (26.3\%). In Question 5, "I had the opportunity to do hands-on drills", 13 students were very satisfied (68.4\%) while four were satisfied (21.1\%) and two had no comment (10.5\%). In Question 6, "I am satisfied with the instructor's teaching style”, 15 students were very satisfied (78.9\%) while four were satisfied (21.1\%). In Question 7, “I understood the teaching contents”, 14 students were very satisfied (73.7\%) while three were satisfied (15.8\%) and two had no comment (10.5\%). In Question 8, "The teaching material was abundant”, 14 students were very satisfied (73.7\%) while five were satisfied (26.3\%). In Question 9, "The course lived up to my expectations", 13 students were very satisfied (68.4\%) while five were satisfied (26.3\%) and one had no comment (5.3\%). In Question 10, "I am very satisfied with the teaching resources”, 15 students were very satisfied (78.9\%) while four were satisfied (21.1\%). In Question 11, "I am very satisfied with today's teaching environment”, 16 students were very satisfied $(84.2 \%)$ while three were satisfied (15.8\%).

Table 1

The Frequency Distribution Table of Week Five's Course (Simple Plumbing) Satisfaction Survey

\begin{tabular}{|c|c|c|c|c|c|c|c|c|}
\hline \multirow{2}{*}{$\begin{array}{l}\text { Objective evaluation on the teaching } \\
\text { content and the instructor }\end{array}$} & \multicolumn{2}{|c|}{ Very satisfied } & \multicolumn{2}{|c|}{ Satisfied } & \multicolumn{2}{|c|}{ No comment } & \multicolumn{2}{|c|}{ Not satisfied } \\
\hline & $N$ & $\%$ & $N$ & $\%$ & $N$ & $\%$ & $N$ & $\%$ \\
\hline 1. I think the course gave me practical help. & 15 & 78.9 & 4 & 21.1 & 0 & 0 & 0 & 0 \\
\hline 2. I think the course was very practical. & 17 & 89.5 & 2 & 10.5 & 0 & 0 & 0 & 0 \\
\hline 3. I think the teaching environment was very comfortable. & 14 & 73.7 & 5 & 26.3 & 0 & 0 & 0 & 0 \\
\hline 4. I think I learned a lot after the course. & 14 & 73.7 & 5 & 26.3 & 0 & 0 & 0 & 0 \\
\hline 5. I had the opportunity to do hands-on drills. & 13 & 68.4 & 4 & 21.1 & 2 & 10.5 & 0 & 0 \\
\hline 6. I am satisfied with the instructor's teaching style. & 15 & 78.9 & 4 & 21.1 & 0 & 0 & 0 & 0 \\
\hline 7. I fully understood the teaching contents. & 14 & 73.7 & 3 & 15.8 & 2 & 10.5 & 0 & 0 \\
\hline 8. The teaching material was abundant. & 14 & 73.7 & 5 & 26.3 & 0 & 0 & 0 & 0 \\
\hline 9. I think the course lived up to my expectations. & 13 & 68.4 & 5 & 26.3 & 1 & 5.3 & 0 & 0 \\
\hline 10. I am very satisfied with the teaching resources. & 15 & 78.9 & 4 & 21.1 & 0 & 0 & 0 & 0 \\
\hline $\begin{array}{l}\text { 11. All in all, I am very satisfied with today's teaching } \\
\text { environment. }\end{array}$ & 16 & 84.2 & 3 & 15.8 & 0 & 0 & 0 & 0 \\
\hline
\end{tabular}

Note. Feedback and encouragement from the mayor, professor, and students was very positive.

\section{Discussion}

\section{Arrangement of the Courses}

The topics of the courses were based on student opinions, so all of them were interested and enthusiastic about the content. If they were present at the workshop, they showed strong involvement. They discussed and practiced what they learned with their family and friends (They were not only learning for personal interests, but also they were doing so for their daily needs).

\section{Teaching Processes}

Hands-on operations were important to adult student learning. Aside from the systematic illustration during the plumbing DIY courses, these opportunities were offered as well. In addition, with 20 years of practical working experience, the researcher was passionate and determined to pass on his professional knowledge. With organized material and enthusiasm, he gave immediate feedback to enhance learning effects 
and decrease the accident rate.

The workshop in the study was carried out for two hours a week. Time was not adequate for students to acquire the necessary skills. However, all material and teaching content were closely related to their lives, while smartphones were also utilized to bridge the gap between instructor and students. Thanks to the developments of modern technology, the teaching process in the study was extended outside the classroom. With the aid of much of this technology, the instructor and students were able to learn and grow together.

\section{Teaching Strategies}

Teaching strategies were divided in five types including: illustration, demonstration, hands-on operation, interactive media of Facebook and LINE, and encouragements.

Illustrations. Illustrations can help students understand and retain information. With the aid of charts and graphs, instructors can make the procedures clear. With greater understanding, adult students will be more involved in the learning process.

Demonstrations. The researcher applied data collected from "very day" life into the class and shared handouts with the students. He also shared relevant online videos for students to review and be able to strengthen their memory at home. The researcher was highly involved in terms of sharing his knowledge and skills with students. This was the key to the success of the workshop. He adapted interactive teaching methods and explained the contents clearly.

Hands-on operations. The teaching context is important in motivating students. With appropriate arrangements, the process can be "half the work and twice the effect". The researcher demonstrated each operation step-by-step and used "real" events to boost their understanding.

With appropriate material and illustrations, adult students can complete the teaching contents successfully, which will give them confidence and a sense of achievement. Figure 8 demonstrates the hands-on operation process for making showerheads.
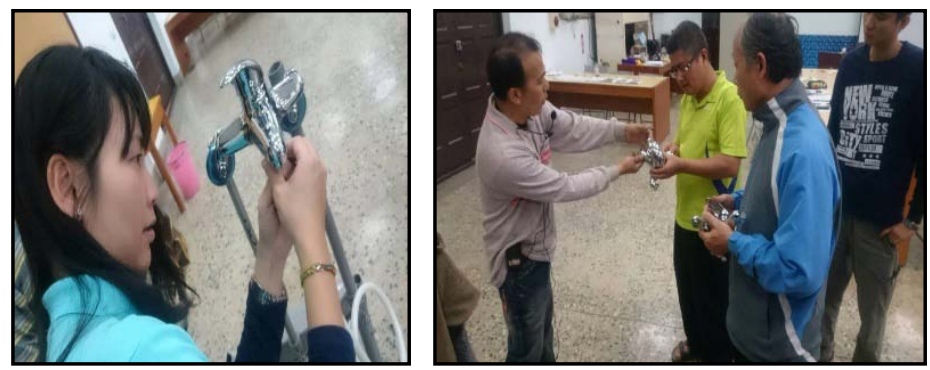

Figure 8. The installation of showerheads.

The use of interactive media. Due to the time limit of the course, students were not able to operate and practice the techniques as well. In order to increase teaching efficiency, Facebook and LINE were set up for them to ask questions after practicing at home. With help from the instructor and fellow students, most of the plumbing problems were solved. This kind of situation is the best example to highlight the success of the plumbing DIY workshop.

Encouragement. On the last day of class, the mayor of the township, advisor Dr. Chung and the sectional chief awarded the training completion certificates and souvenirs to all students in person. The purpose was to commend the researcher's work and the student's participation. Sixteen-hour course certifications were provided to all students who participated through the course. 


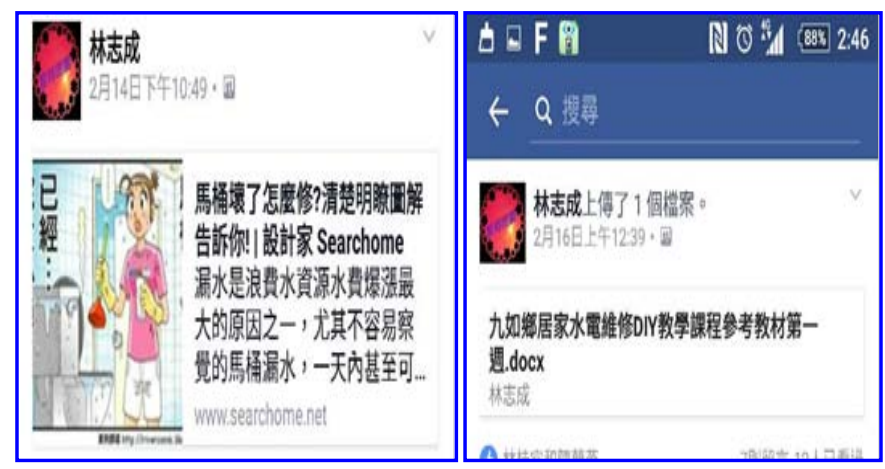

Figure 9. Online teaching materials.

\section{Conclusions and Implications}

The course in this study was based on the needs of adult learners. However, all students possessed a strong learning motivation for the material. In addition, the instructor's enthusiasm was a key element in its success. With 20 years of experience, the instructor took students' learning needs into consideration and prepared well-organized material and handouts, which made the teaching process practical. The idea of "learning by doing” or "learning by practice" was an excellent endorsement of the workshop.

This teaching activity was done in a typical skill-learning mode. First came the instructor's illustration, and then came his hands-outs on operations, practices, and discussions between students and teacher, including his immediate feedback. During the illustration process, the instructor emphasized dismantling the plumbing DIY materials into simple tasks: By using step-by-step demonstration, he guided students to do hands-on drills. They were encouraged to discuss and ask for advice from one another (or from the instructor) during the process. This prompt feedback was an indispensable element in skill learning.

Given the development of modern technology, there are relevant videos on YouTube. Integrated with plumbing DIY course illustrations, replays of the videos were helpful in making the teaching process easier. In addition, students could use smartphones to film and raise questions via Facebook and LINE to get guidance from the instructor, whether simultaneously or asynchronously. DIY plumbing expanded outside the classroom, which underlined students' active involvement, as well as the aid of modern technology.

\section{References}

Cant, R. P., \& Cooper, S. J. (2010). Simulation-based learning in nurse education: Systematic review. Journal of Advanced Nursing, 66(1), 3-15.

Driscoll, M. P. (2005). Psychology of learning for instruction (3rd ed.). Boston: Pearson.

Gould, R. (2010). Statistics and the modern student. International Statistical Review, 78(2), 297-315.

Huang, H. M. (2002). Toward constructivism for adult learners in online learning environments. British Journal of Educational Technology, 33(1), 27-37.

Jongbloed-Pereboom, M., Janssen, A. J., Steenbergen, B., \& Nijhuis-van der Sanden, M. W. (2012). Motor learning and working memory in children born preterm: A systematic review. Neuroscience \& Biobehavioral Reviews, 36(4), 1314-1330.

Katz, R. L. (2009). Skills of an effective administrator. Boston, MA: Harvard Business Review Press.

Kellogg, R. T. (2008). Training writing skills-A cognitive developmental perspective. Journal of Writing Research, 1(1), $1-26$.

Lasater, K., Johnson, E. A., Ravert, P., \& Rink, D. (2014). Role modeling clinical judgment for an unfolding older adult simulation. Journal of Nursing Education, 53(5), 257-264.

Lei, J. (2009). Digital natives as preservice teachers: What technology preparation is needed? Journal of Computing in Teacher Education, 25(3), 87-97. 
Shih, J. L., Chuang, C. W., \& Hwang, G. J. (2010). An inquiry-based mobile learning approach to enhancing social science learning effectiveness. Educational Technology \& Society, 13(4), 50-62.

Test Rite Retail. (2011). Test rite retail DIY showerheads. Retrieved May 31, 2011, from https://www.youtube.com/watch?v=fduaigDCr8g

Test Rite Retail. (2015). Test rite retail: The installation of facial faucets. Retrieved December 2, 2015, from https://www.youtube.com/watch?v=XqBXnF-O_BA

Yunus, M. M., \& Salehi, H. (2012). The effectiveness of Facebook groups on teaching and improving writing: Students' perceptions. Journal of Education and Information Technologies, 1(6), 87-96. 